\section{Clinical development of CT-P10 and other biosimilar cancer therapeutics}

\author{
Won Seog Kim*, ${ }^{*}$ Bertrand Coiffier ${ }^{2}$, Hyuk-Chan Kwon ${ }^{3}$ \& SuYeon Kim³
}

\begin{abstract}
Biosimilars are highly similar versions of approved biologic drugs that may confer equivalent efficacy at a reduced cost. Patents for several biological cancer therapeutics are past or approaching expiry, presenting an opportunity to increase affordability and global accessibility of key drugs through the development of biosimilars. To receive approval, a biosimilar must show no clinically meaningful differences from the reference product in terms of efficacy or safety. The first monoclonal antibody biosimilar cancer therapeutic to gain approval was CT-P10, a biosimilar of rituximab. Here, we review the oncology clinical development program for CT-P10, providing insights into the rationale for, and design of, CT-P10 clinical trials in patients with cancer. Trials of biosimilar cancer therapeutics in development are also discussed.
\end{abstract}

First draft submitted: 30 March 2017; Accepted for publication: 20 April 2017; Published online: 9 May 2017

Biological products - including monoclonal antibodies, cell therapies, cytokines and growth factors - are essential components of the oncology treatment arsenal. However, they are expensive, which can impose limitations on their use. A biosimilar is a biological product that is highly similar to an already approved biologic drug, referred to as the reference product, and which shows 'no clinically meaningful differences [from the reference product] in terms of safety, purity and potency' [1]. The active substance of a biosimilar medicine is a known biologically active substance similar to that of the reference product. A similar biological medicinal product and its reference medicinal product are expected to have the same safety and efficacy profile and are used to treat the same conditions [2]. Biosimilars are generally more affordable than their reference products, and thus have the potential to change the landscape of cancer treatment by increasing global access to key drugs.

In February 2017, the first monoclonal antibody biosimilar cancer therapeutic received international regulatory approval when the EMA granted market authorization to CT-P10 (Truxima ${ }^{\circledR}$; CELLTRION, Incheon, Republic of Korea), a biosimilar of the anti-CD20 monoclonal antibody, rituximab [3]. This decision followed the approval of CT-P10 in South Korea in November 2016. CT-P10 and reference rituximab - which is known by the brand names MabThera ${ }^{\circledR}$ (Roche, Basel, Switzerland) in Europe and Rituxan ${ }^{\circledR}$ (Genentech, CA, USA) in the USA and is subsequently abbreviated as 'RTX' - are monoclonal antibodies that bind to the anti-CD20 antigen on the surface of normal and malignant $\mathrm{B}$ cells. This binding triggers B-cell destruction via mechanisms including antibody-dependent cell-mediated cytotoxicity, complement-dependent cytotoxicity and the induction of apoptosis [4]. CT-P10 has an identical amino acid sequence to RTX as well as highly

'Sungkyunkwan University School of Medicine, Samsung Medical Center, Seoul, Republic of Korea

${ }^{2}$ Hospices Civils de Lyon, Pierre-Benite, France

${ }^{3}$ CELLTRION Healthcare Co. Ltd, Incheon, Republic of Korea

*Author for correspondence: Tel.: +82 23410 6548; Fax: +82 23410 1757; wskimsmc@skku.edu

\section{KEYWORDS}

- bevacizumab $\bullet$ biosimilars

- cetuximab • CT-P10

- oncology $\bullet$ rituximab

- trastuzumab 
similar physicochemical and in vitro functional properties [3].

European approval of CT-P10 was granted for all indications held by RTX, including rheumatoid arthritis (RA) and two forms of vasculitis, plus non-Hodgkin's lymphoma and chronic lymphocytic leukemia. In non-Hodgkin's lymphoma, CT-P10 is approved for use in previously untreated patients with stage III-IV follicular lymphoma (FL) in combination with chemotherapy, as maintenance therapy in FL patients responding to induction therapy and as monotherapy in patients with stage III-IV FL who are chemoresistant or in their second or subsequent relapse after chemotherapy. It is also approved for treatment of CD20-positive diffuse large B-cell lymphoma in combination with CHOP (cyclophosphamide, doxorubicin, vincristine, prednisolone) chemotherapy. In chronic lymphocytic leukemia, CT-P10 is indicated for the treatment of patients with previously untreated or relapsed/refractory disease, alone or in combination with chemotherapy.

The decision by the EMA to approve CT-P10 was based on review of all available data, including the results of direct comparisons with RTX in analytical, in vitro and nonclinical in vivo studies, and clinical trials [5]. By considering all the available data - often referred to as the 'totality of evidence' - the EMA concluded that there are likely to be no clinically significant differences in efficacy or safety between CT-P10 and RTX in any of the indications held by RTX. As CT-P10 is the first monoclonal antibody biosimilar to be approved as a treatment for cancer, there is much interest in the studies that led to its approval. For physicians, clinical trials of CT-P10 may be of particular interest. This article will review the oncology clinical development program for CT-P10, providing insights into the rationale for, and design of, CT-P10 clinical trials, before providing an overview of available information on trials of other biosimilar cancer therapeutics in development.

\section{Oncology clinical trials of CT-P10}

The approval pathway for biosimilars follows a well-defined stepwise process. The reference product and candidate biosimilar are compared first in terms of nonclinical characteristics, and then with respect to different clinical properties (e.g., pharmacokinetics [PK], efficacy and safety) [6]. The results at each step of the process inform the design and size of subsequent studies. If major differences emerge between the biosimilar and the reference product at any stage, the decision to follow the biosimilar approval pathway must be re-evaluated. Importantly, the aim of biosimilar development is not to establish the safety and efficacy of the biosimilar per se. Instead, it is to show that the biosimilar does not differ in any clinically meaningful way from the reference product, so that the safety and efficacy data for the reference product can also be applied to the biosimilar [7]. As a result, the approval process for biosimilars is accelerated compared with that of new biologic drugs, although it is considerably longer and more complex than that of small-molecule generic drugs. The size and scope of the clinical studies required vary from one biosimilar to the next, and depend on the extent to which equivalence of nonclinical characteristics is shown $[1,7]$.

Often the first aim of the clinical program for a biosimilar candidate is to determine its equivalence to the reference product in terms of PK, usually in Phase I randomized controlled trials recruiting healthy volunteers or patients. Of note, both the EMA and the US FDA recommend the use of a parallel design for Phase I studies of monoclonal antibodies owing to the long half-life of these products $[1,8]$. The primary aim in terms of PK testing is to ensure that systemic exposures, quantified as the area under the serum concentration-time curve (AUC) and maximum serum concentration $\left(\mathrm{C}_{\max }\right)$, are statistically equivalent between biosimilar and reference product [9]. Clinical trials for establishing similarity in efficacy, usually labelled as Phase III studies, typically adopt one of two randomized designs: equivalence or noninferiority. An equivalence trial aims to show that any difference between the biosimilar and the reference product does not exceed the predetermined 'minimum clinically important difference.' This difference is defined using data from past clinical studies of the reference product, although not necessarily from the trials that led to its approval. The aim of a noninferiority trial is to show that the biosimilar is at least as effective as the reference product. Both Phase I and Phase III biosimilar studies are usually also utilized to collect important data on the comparability of pharmacodynamics (PD), immunogenicity and safety.

One of the key trials that led to the approval of the RTX biosimilar CT-P10 was a doubleblind, randomized controlled Phase III study in 
patients with FL [10-12]. The aim of the study was to demonstrate equivalence of $\mathrm{PK}$ and noninferiority of efficacy of CT-P10 to US-sourced RTX (US-RTX; Rituxan) when coadministered with cyclophosphamide, vincristine and prednisone (CVP) in patients with previously untreated advanced-stage FL. Enrolled patients had histologically confirmed CD20-positive FL of grade 1 to grade 3a, Ann Arbor stage III or IV disease with at least one measurable nonirradiated tumor mass and adequate bone marrow, hepatic and renal function. During the initial induction period, patients were administered intravenous infusions of $375 \mathrm{mg} / \mathrm{m}^{2}$ CT-P10 or RTX, plus CVP, at 3-weekly intervals over 24 weeks (Figure 1) [10-12]. Patients who respond to treatment during this time continued CT-P10 or RTX alone as maintenance therapy.

The FL study was divided into two parts. The aim of part 1 was to demonstrate equivalent $\mathrm{PK}$ via two primary end points: $\mathrm{AUC}$ at steady state $\left(\mathrm{AUC}_{\text {tau }}\right)$ and $\mathrm{C}_{\text {max }}$ at steady state $\left(\mathrm{C}_{\text {max }, S S}\right)$ at cycle 4 of the induction period. In accordance with EMA guidelines, a single dose was tested as this design provides greater sensitivity for detecting differences in PK than a multiple-dose study [9]. Guidelines also state that comparability limits for key PK parameters must be specified in advance of the study [7]. In the FL study, the prespecified equivalence criterion was that the $90 \%$ CIs for the ratio (CT-P10 to RTX) in geometric least squares mean values for $\mathrm{AUC}_{\text {tau }}$ and $\mathrm{C}_{\text {max }, S S}$ should be within the bounds of the equivalence margin of $80-125 \%$, in accordance with EMA guidelines [9].

The aim of part 2 of the FL study was to demonstrate noninferior efficacy of CT-P10 compared with RTX. With respect to efficacy comparisons, the most sensitive patient population and end points should be used so that any differences between the reference product and biosimilar may be detected [7]. A patient population with FL was therefore chosen because FL shows slow disease progression over a long period of time. As the main objective of the study was to establish PK equivalence of CT-P10 and RTX, a homogenous population (FL) was selected to increase sensitivity. Diffuse large B-cell lymphoma, by contrast, would have been unsuitable because it encompasses a biologically and clinically diverse range of diseases, and shows a natural progression that makes it unsuitable for evaluating treatment efficacy through overall response rate (ORR). Although survival end points - progression-free survival (PFS) or overall survival (OS) - are generally preferred for establishing the efficacy of new treatments in cancer, these end points may not be sensitive enough to assess biosimilarity. The EMA therefore recommends that the primary end point should instead be a clinical end point that measures disease activity (e.g., ORR or pathological complete response [pCR]). The FDA advises a similar overall approach, and also encourages the use of PD end points if available [1]. Therefore, the CT-P10 trial in FL, in common with other clinical trials for candidate RTX biosimilars (Table 1), used ORR as the primary clinical end point, even though this was not the primary end point in the pivotal RTX trials. ORR was defined as the proportion of responders who achieved a partial or complete response over eight cycles. In contrast to survival, ORR can be assessed at a much earlier time point, and is less likely to be confounded by differences in patient and disease characteristics. To characterize the longer term clinical safety and efficacy of CT-P10, the FL study will also include follow-up assessments until death or 3 years from the first day of induction cycle 1 for the last patient, in order to allow determination of PFS and OS.

A double-blind, randomized controlled Phase III trial comparing CT-P10 with RTX in lowtumor-burden FL is also ongoing [23]. Patients will be randomized to receive four cycles of CT-P10 or RTX during the induction period (Figure 2). Individuals who show at least a partial response will then enter the maintenance phase, in which they will receive treatment every 2 months for up to 24 months. Patients who received CT-P10 in the induction period will receive up to 12 cycles of CT-P10 in the maintenance period; those who were initially treated with RTX will receive an additional six cycles of RTX, followed by six cycles of CT-P10. The primary outcome will be ORR at month 7 , assessed prior to cycle 3 of the maintenance period. Secondary outcomes will include ORR over the entire study period, PFS, time to progression, OS and PK measures.

Some data from the induction period of the Phase III study of CT-P10 in advanced-stage FL are now available and are summarized in greater detail elsewhere [5]. In brief, analyses at week 12 after cycle 4 of the induction period showed that CT-P10 and RTX displayed highly similar PK, PD and safety [12]. The $90 \%$ CIs of the ratio of geometric least squares means for $\mathrm{AUC}_{\mathrm{tau}}$ and 


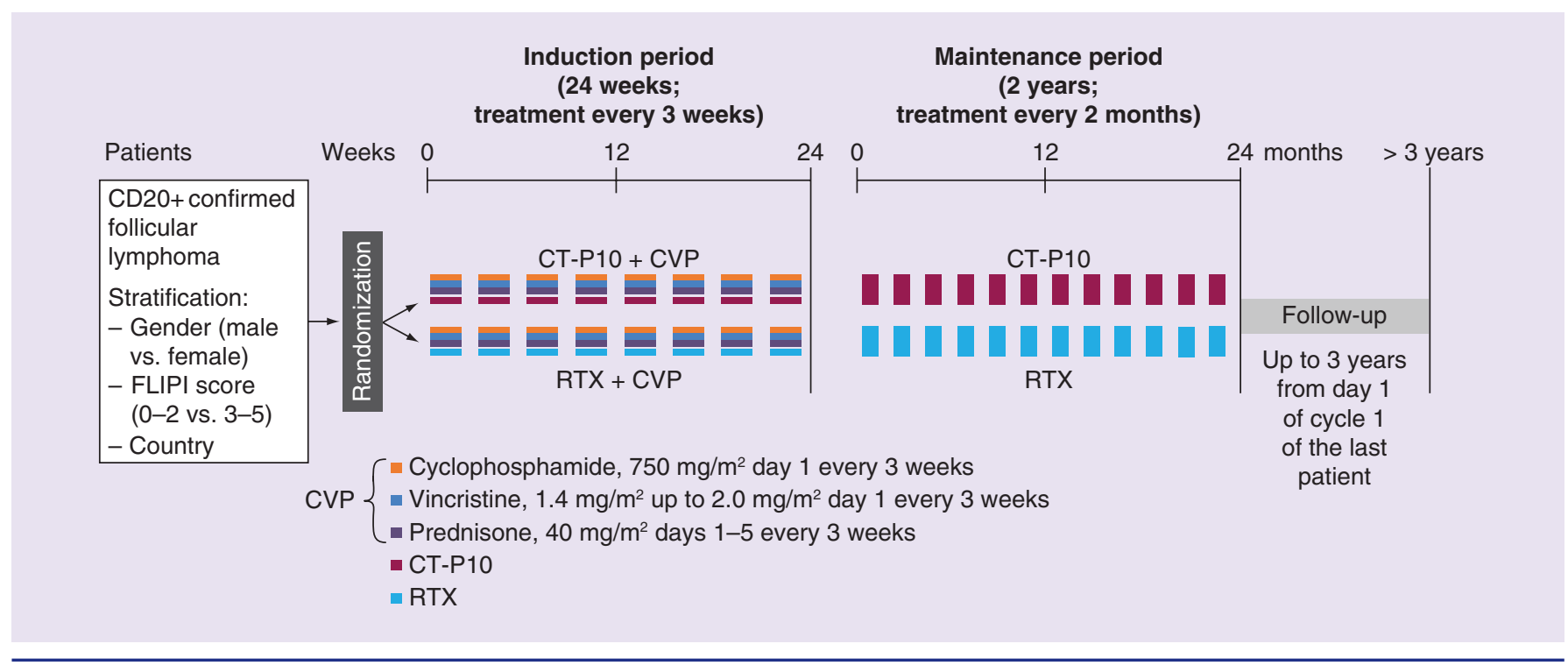

Figure 1. Design of the Phase III randomized controlled trial of CT-P10 versus reference rituximab in patients with advanced follicular lymphoma. Patients were randomized to receive eight cycles of CT-P10 or RTX given every 3 weeks for 24 weeks, alongside CVP chemotherapy (induction period). Patients who achieved at least a partial response after 24 weeks of treatment could continue on maintenance therapy for 2 years (CT-P10 or RTX given at 2-monthly intervals).

CVP: Cyclophosphamide, vincristine and prednisone; FLIPI: Follicular Lymphoma International Prognostic Index; RTX: Reference rituximab.

$\mathrm{C}_{\max S S}$ were fully contained within the predefined equivalence margins. Median B-cell count decreased below the lower limit of detection $1 \mathrm{~h}$ after infusion of either CT-P10 or RTX and remained below this limit up to induction cycle 4. CT-P10 was well tolerated with a similar safety profile to the reference product. The proportion of patients with an antidrug antibody response was comparable between treatment groups [12].

\section{Extrapolation of indications}

The clinical trials necessary to establish biosimilarity between a candidate biosimilar and the reference product are typically conducted in only one or two indications. However, once biosimilarity has been proven in these trials (and in analytical, functional and other nonclinical studies), EMA, FDA and other guidelines all allow approval of the biosimilar to be extended to other indications held by the reference product, providing that this is scientifically justified $[1,7,24]$. The scientific justification for such extrapolation of clinical data across indications must be based on consideration of multiple factors, including the mechanisms of action (MoAs) of the reference product in both the extrapolated and clinically tested populations, and the comparability of the two products in MoA-related functional tests. The decision whether to permit extrapolation is made on a case-by-case basis for each biosimilar and each potential indication. Any residual uncertainties must be addressed through the provision of additional clinical data.

The EMA approved CT-P10 for all indications held by RTX on the basis of the data collected in FL, additional clinical data that were collected in studies recruiting patients with RA and a scientific rationale that included consideration of MoAs and functional testing [25]. Two randomized controlled trials were performed to compare the profiles of CT-P10 and RTX in patients with RA. In a Phase I study, CT-P10 and EU-sourced RTX (EU-RTX) showed equivalent $\mathrm{PK}$ characteristics, and comparable PD, safety, immunogenicity and efficacy [13]. A subsequent Phase III study demonstrated PK equivalence between CT-P10 and both EU-RTX and US-RTX [14]. The same study showed equivalent efficacy and highly similar PD and safety profiles between CT-P10 and RTX treatment groups at week 24 [15].

\section{Clinical trials of other biosimilar cancer therapeutics}

CT-P10 is currently the only rituximab biosimilar approved in Europe. However, several candidate biosimilars of this drug are also in development (Table 1). Biosimilar candidates of other 


\section{Table 1. Clinical trials of CT-P10 and key candidate rituximab biosimilars.}

\begin{tabular}{|c|c|c|c|}
\hline Biosimilar & Study details & Status/published results & Ref. \\
\hline \multirow[t]{2}{*}{ CT-P10 (CELLTRION) } & $\begin{array}{l}\text { Phase: I } \\
\text { Indication: RA } \\
\text { Concomitant treatment: MTX } \\
\mathrm{n}=154 \\
\left.\text { Primary end point: PK (AUC }{ }_{0-\text { last' }} \mathrm{C}_{\max }\right) \\
\text { Design: equivalence }\end{array}$ & $\begin{array}{l}\text { Complete } \\
\text { Equivalent PK demonstrated for CT-P10 vs EU-RTX, and } \\
\text { comparable PD, efficacy, safety and immunogenicity } \\
\text { Geometric means ratio CT-P10/EU-RTX }(90 \% \text { Cl): } \\
\text { - AUC } \text {-last' }^{\prime} 0.98(0.89,1.07) \\
\text { - } C_{\text {max' }^{\prime}} 0.98(0.92,1.04)\end{array}$ & {$[13]$} \\
\hline & $\begin{array}{l}\text { Phase: III } \\
\text { Indication: untreated advanced FL } \\
\text { Concomitant treatment: CVP } \\
\mathrm{n}=121 \\
\text { Primary end point: } \mathrm{PK}\left(\mathrm{AUC}_{\mathrm{tau}} \mathrm{C}_{\text {max,sS }}\right) \\
\text { Design: equivalence }\end{array}$ & $\begin{array}{l}\text { Complete } \\
\text { Equivalent PK demonstrated for CT-P10 vs US-RTX and } \\
\text { comparable PD, safety and immunogenicity } \\
\text { Geometric LS means ratio }(90 \% \mathrm{CI}): \\
\text { - AUC }{ }_{\text {tau' }} 1.02(0.94,1.11) \\
\text { - } \text { C }_{{\text {max }, S S^{\prime}}^{\prime}} 1.01(0.94,1.08)\end{array}$ & {$[12]$} \\
\hline GP2013 (Sandoz) & $\begin{array}{l}\text { Phase: I } \\
\text { Indication: RA } \\
\text { Concomitant treatment: NR } \\
\mathrm{n}=173 \\
\text { Primary end point: } \mathrm{PK}\left(\mathrm{AUC}_{0-\infty}\right) \\
\text { Design: equivalence }\end{array}$ & $\begin{array}{l}\text { Complete } \\
\text { Equivalent PK and PD demonstrated for GP2013 vs EU-RTX } \\
\text { and noninferiority in terms of efficacy } \\
\text { Geometric means ratio GP2013/RTX: } \\
\text { - AUC }{ }_{0-\infty{ }^{\prime}} 1.06 \\
\text { - B-cell depletion, } 1.02 \\
\text { - } 90 \% \text { Cls within } 0.8-1.25 \text { margins }\end{array}$ & $w[17]$ \\
\hline PF-05280586 (Pfizer) & $\begin{array}{l}\text { Phase: I } \\
\text { Indication: RA } \\
\text { Concomitant treatment: MTX } \\
\mathrm{n}=220 \\
\text { Primary end point: PK }\left(\mathrm{C}_{\text {max' }} \mathrm{AUC}_{0-\infty}\right) \\
\text { Design: equivalence }\end{array}$ & 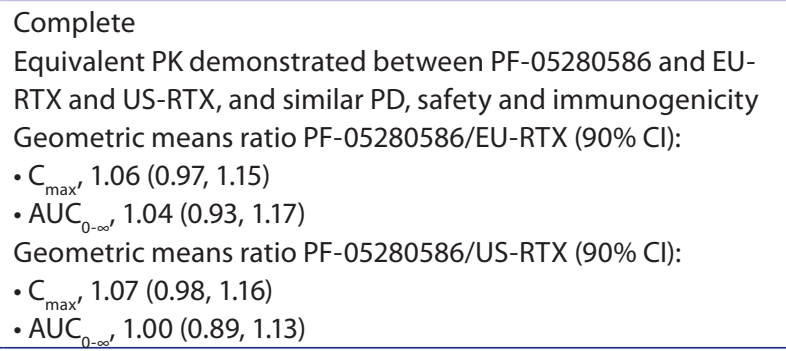 & {$[18]$} \\
\hline
\end{tabular}


Table 1. Clinical trials of CT-P10 and key candidate rituximab biosimilars (cont.).

\begin{tabular}{|c|c|c|c|}
\hline \multirow[t]{2}{*}{ Biosimilar } & Study details & Status/published results & Ref. \\
\hline & $\begin{array}{l}\text { Phase: III } \\
\text { Indication: low-tumor-burden FL } \\
\text { Concomitant treatment: none } \\
\mathrm{n}=394 \text { (estimated) } \\
\text { Primary end point: ORR at week } 26 \\
\text { Design: equivalence }\end{array}$ & $\begin{array}{l}\text { Ongoing } \\
\text { Estimated completion date: June } 2018\end{array}$ & [19] \\
\hline ABP 798 (Amgen) & $\begin{array}{l}\text { Phase: III } \\
\text { Indication: low-tumor-burden FL } \\
\text { Concomitant treatment: none } \\
\mathrm{n}=250 \text { (estimated) } \\
\text { Primary end point: risk difference of ORR } \\
\text { at } 28 \text { weeks } \\
\text { Design: NR }\end{array}$ & $\begin{array}{l}\text { Ongoing } \\
\text { Estimated completion date: March } 2018\end{array}$ & {$[20,22]$} \\
\hline
\end{tabular}

targeted therapies are also emerging as their reference products near or reach patent expiry (Table 2). Patents on cetuximab (Erbitux ${ }^{\circledR}$; Lilly and Company, NJ, USA), an EGFR inhibitor used in KRAS wild-type metastatic colorectal cancer, and head and neck cancer, expired in the USA in February 2016 and in Europe in June 2014. The patent for trastuzumab (Herceptin ${ }^{\circledR}$; Genentech, CA, USA), a monoclonal antibody that is used for the treatment of HER2-positive breast cancer and metastatic gastric cancer, has already expired in Europe and is expected to expire in the USA in June 2019. This will be followed by patents for bevacizumab (Avastin ${ }^{\circledR}$; Genentech, CA, USA) in the USA and then Europe. Reported and ongoing trials of key biosimilar candidates of these drugs are discussed below.

\section{- Clinical trials of rituximab biosimilar candidates}

GP2013 was accepted for review by the EMA in May 2016. This application was based in part on data from clinical trials in FL and RA. A Phase III trial in patients with untreated advanced FL compared GP2013 with RTX in combination with CVP [16]. In a similar design to the Phase III trial of CT-P10 in FL, this study consisted of an initial combination treatment phase of 6 months' duration in which patients received up to eight cycles of GP2013 + CVP or RTX + CVP, followed by maintenance treatment with GP2013 or RTX monotherapy for 2 years. The primary efficacy end point of ORR was assessed after the combination phase, which has now been completed. Equivalence of the primary efficacy end point was demonstrated between GP2013 and RTX. Similarity between treatment arms was demonstrated in PK, PD and immunogenicity; no new safety signals were detected [16].

Two Phase III trials are underway assessing the comparability of another rituximab biosimilar candidate, ABP 798, with RTX in patients with RA or low-tumor-burden FL. In the latter, patients will be treated with RTX or ABP 798 monotherapy weekly for 4 weeks then at weeks 12 and 20 . The primary end point is risk difference of overall response rate at week 28 [20].

Trials of a third candidate RTX biosimilar, PF-05280586, are summarized in Table 1. Of additional note, several 'biomimics' or 'intended copies' of RTX have been approved in countries with less stringent regulatory environments than those in Europe, the USA and elsewhere. These agents have not undergone the rigorous comparability testing required by the EMA and FDA. The efficacy of these agents has not been established in high-quality clinical trials and question marks remain over their safety [42]. 


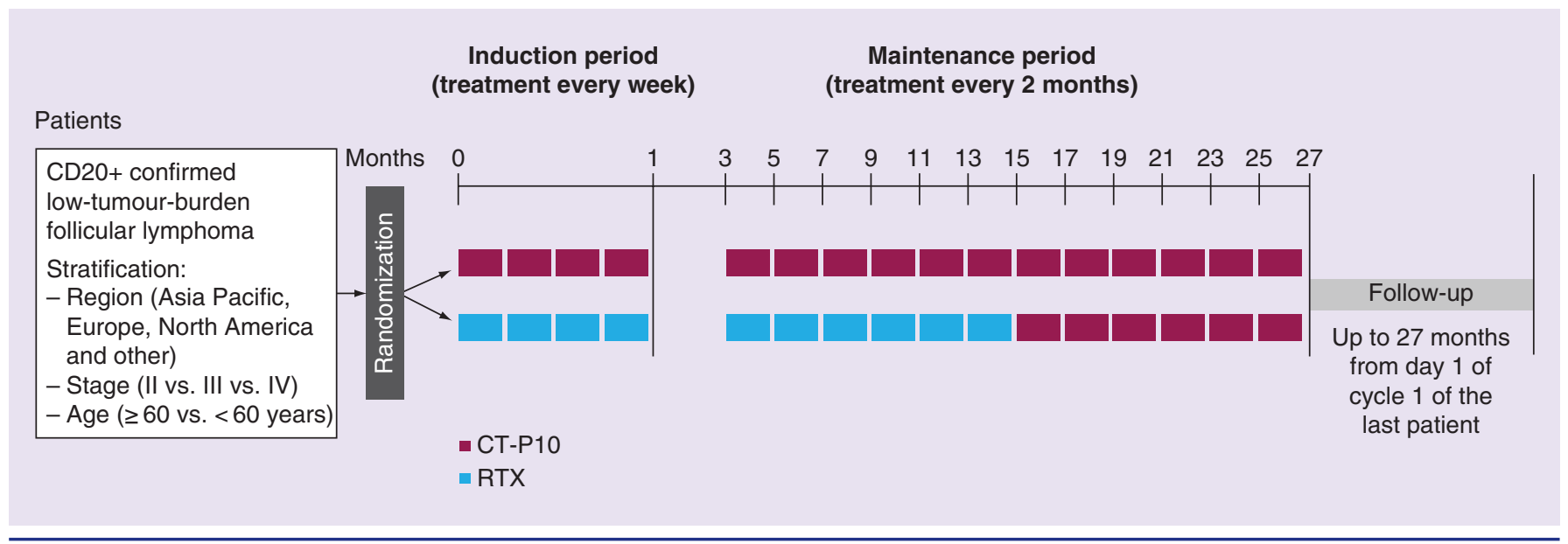

Figure 2. Design of the Phase III randomized controlled trial of CT-P10 versus reference rituximab in patients with low-tumorburden follicular lymphoma. Patients will be randomized to receive four cycles of CT-P10 or RTX given every week for 4 weeks (induction period). Patients who show at least a partial response after 4 weeks of treatment can continue on maintenance therapy for 2 years (CT-P10 or RTX given at 2-monthly intervals).

RTX: Reference rituximab.

\section{- Clinical trials of cetuximab biosimilars}

Although patents on cetuximab have expired, few biosimilar candidates of this biologic have reached the point of clinical evaluation. CMAB009, a recombinant anti-EGFR monoclonal antibody with the same amino acid sequence as cetuximab has been evaluated in a Phase I study. The antibody was administered to 18 Chinese patients with advanced chemotherapy-resistant epithelial malignancies, two of whom achieved partial remission [26]. A Phase II/III study of CMAB009 for the treatment of KRAS wild-type metastatic colorectal cancer has also been completed [27]. However, CMAB009 is manufactured using a different expression system to cetuximab and has a different final product formulation. It is therefore unclear whether CMAB009 can truly be considered a cetuximab biosimilar candidate.

Similarly, STI-001, a cetuximab 'copy biological,' has undergone Phase III testing in patients with EGFR-expressing metastatic colorectal carcinoma [43]. STI-001 improved ORR, PFS and OS when administered in combination with irinotecan compared with irinotecan alone. However, STI-001 is also produced using a different expression system to cetuximab and has a nonidentical composition. In common with CMAB009, therefore, it is not clear that STI-001 can be regarded as a true biosimilar candidate.

\section{- Clinical trials of trastuzumab biosimilars}

Several biosimilar candidates of trastuzumab are currently in development, three of which
- MYL-1401O, CT-P6 and SB3 - were submitted for approval to the EMA in 2016. MYL14010 has also been submitted for approval to the FDA.

PK equivalence of MYL-1401O and both EU- and US-sourced reference trastuzumab has been demonstrated in a double-blind, three-arm Phase I trial in healthy male volunteers [29]. In a Phase III study, the efficacy and safety of MYL14010 was compared with that of reference trastuzumab in patients with HER2-positive metastatic breast cancer as first-line treatment in combination with docetaxel or paclitaxel. Patients were randomized 1:1 to receive at least eight cycles of the treatment combination. Equivalent efficacy was demonstrated, as the $95 \%$ CI of the ratio of the primary end point, ORR at week 24, fell within the predefined equivalence margin. Similar safety profiles were also observed between treatment groups [30].

A Phase I study has assessed the PK equivalence of CT-P6 and reference trastuzumab in healthy male volunteers [31] while an ongoing Phase III study [32] is investigating the equivalence of CT-P6 and reference trastuzumab in terms of $\mathrm{pCR}$ in patients undergoing neoadjuvant therapy for HER2-positive early breast cancer [32]. Data from these studies are yet to be published.

PF-05280014 has demonstrated PK equivalence to both EU- and US-sourced reference trastuzumab in healthy volunteers [33]. A Phase III trial in patients with HER2-positive 
SUPPLEMENT Kim, Coiffier, Kwon \& Kim

Table 2. Clinical trials of other key biosimilars in development for the treatment of cancer.

\begin{tabular}{|c|c|c|c|}
\hline Biosimilar & Study details & Status/published results & Ref. \\
\hline \multicolumn{4}{|l|}{ Cetuximab biosimilars ${ }^{\dagger}$} \\
\hline \multirow{3}{*}{$\begin{array}{l}\text { CMAB009 (Shanghai Zhangjiang } \\
\text { Biotechnology) }\end{array}$} & Phase: I & Complete & [26] \\
\hline & $\begin{array}{l}\text { Indication: advanced epithelial malignancies } \\
\text { Concomitant treatment: none } \\
\mathrm{n}=18 \\
\text { Primary end point: PK }\end{array}$ & $\begin{array}{l}\text { Acceptable PK profiles after single and multiple } \\
\text { dosing. CMAB009 was well tolerated }\end{array}$ & \\
\hline & $\begin{array}{l}\text { Phase: III } \\
\text { Indication: KRAS WT metastatic colorectal } \\
\text { cancer } \\
\text { Concomitant treatment: irinotecan } \\
\mathrm{n}=512 \\
\text { Primary end point: ORR }\end{array}$ & $\begin{array}{l}\text { Complete } \\
\text { (data not yet available) }\end{array}$ & [27] \\
\hline STI-001 (Sorrento Therapeutics) & $\begin{array}{l}\text { Phase: III } \\
\text { Indication: EGFR+ metastatic colorectal cancer } \\
\text { Concomitant treatment: irinotecan/none } \\
\mathrm{n}=501 \\
\text { Primary end point: NR }\end{array}$ & $\begin{array}{l}\text { STI-001 plus irinotecan was significantly more } \\
\text { effective than irinotecan alone } \\
\text { - ORR, } 32.9 \text { vs } 12.8 \% \\
\text { - PFS, } 5.6 \text { vs } 3.2 \text { months } \\
\text { - OS, } 14.1 \text { vs } 13.4 \text { months }\end{array}$ & [28] \\
\hline \multicolumn{4}{|l|}{ Trastuzumab biosimilars } \\
\hline \multirow[t]{2}{*}{ MYL-14010 (Mylan) } & $\begin{array}{l}\text { Phase: I } \\
\text { Indication: none (healthy volunteers) } \\
\text { Concomitant treatment: none } \\
\mathrm{n}=132 \\
\text { Primary end point: } \mathrm{PK}\left(\mathrm{C}_{\text {max }^{\prime}} \mathrm{AUC}_{0-\infty^{\prime}}, \mathrm{AUC}_{0-\text { last }}\right) \\
\text { Design: equivalence }\end{array}$ & $\begin{array}{l}\text { Complete } \\
\text { PK equivalence demonstrated for MYL-14010 } \\
\text { vs EU-TTZ and US-TTZ } \\
\text { LS means ratio MYL-1401O/EU-TTZ }(90 \% \mathrm{Cl}) \text { : } \\
\text { - } \mathrm{C}_{\text {max' }^{\prime}} 1.04(0.99,1.10) \\
\text { - AUC } \\
\text { - } \text { AUC }_{0-\infty^{\prime}} 0.97(0.91,1.03) \\
\text { LS meast' }^{\prime} 0.97(0.91,1.03) \\
\text { - } C_{\text {max }^{\prime}} 1.02(0.96,1.07) \\
\text { - AUC } \\
\text { - } \text { AUC }_{0-\infty^{\prime}} 0.96(0.90,1.02) \\
0.96(0.90,1.02)\end{array}$ & [29] \\
\hline & $\begin{array}{l}\text { Phase: III } \\
\text { Indication: HER2+ metastatic breast cancer } \\
\text { Concomitant treatment: docetaxel or paclitaxel } \\
\mathrm{n}=458 \\
\text { Primary end point: ORR at week } 24 \\
\text { Design: equivalence }\end{array}$ & $\begin{array}{l}\text { Complete } \\
\text { Equivalent efficacy demonstrated for MYL- } \\
14010 \text { vs TTZ } \\
\text { - ORR, } 69.6 \text { vs } 64.0 \% \\
\text { - ORR ratio }(90 \% \mathrm{Cl}), 1.09(0.974,1.211) \\
\text { - TTP at week } 48,41.3 \text { vs } 43.0 \% \\
\text { - PFS at week } 48,44.3 \text { vs } 44.7 \% \\
\text { - OS at week } 48,89.1 \text { vs } 85.1 \%\end{array}$ & [30] \\
\hline \multirow[t]{2}{*}{ CT-P6 (CELLTRION) } & $\begin{array}{l}\text { Phase: I } \\
\text { Indication: none (healthy volunteers) } \\
\text { Concomitant treatment: none } \\
\mathrm{n}=70 \\
\text { Primary end point: PK ( } \mathrm{AUC} \mathrm{C}_{0-\infty^{\prime}} \mathrm{AUC}_{0-\text { last' }^{\prime}} \mathrm{C}_{\text {max }} \text { ) } \\
\text { Design: equivalence }\end{array}$ & $\begin{array}{l}\text { Complete } \\
\text { PK equivalence demonstrated for CT-P6 vs TTZ } \\
\text { Geometric LS means ratio CT-P6/TTZ }(90 \% \text { Cl): } \\
\text { - AUC } \\
\text { - } \text { AUC }_{0-o^{\prime}} 0.99(0.93,1.06) \\
\text { - } C_{\text {max }^{\prime}} 0.99(0.99(0.93,1.06) \\
0.91,1.03)\end{array}$ & [31] \\
\hline & $\begin{array}{l}\text { Phase: III } \\
\text { Indication: HER2+ early breast cancer } \\
\text { Concomitant treatment: neoadjuvant } \\
\text { chemotherapy } \\
\mathrm{n}=562 \\
\text { Primary end point: } \mathrm{pCR} \\
\text { Design: equivalence }\end{array}$ & $\begin{array}{l}\text { Ongoing } \\
\text { Estimated completion date: June } 2019\end{array}$ & [32] \\
\hline \multicolumn{4}{|c|}{ 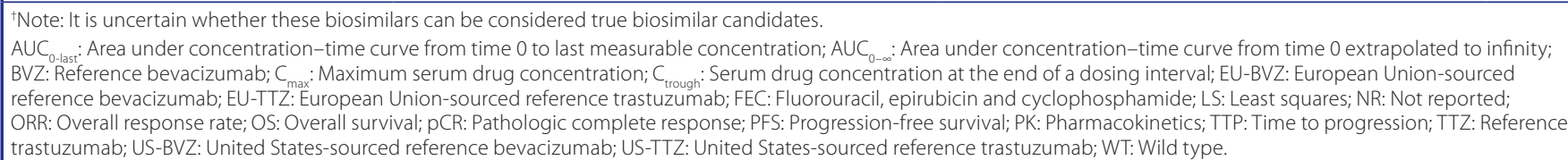 } \\
\hline
\end{tabular}


Table 2. Clinical trials of other key biosimilars in development for the treatment of cancer (cont.).

\begin{tabular}{|c|c|c|c|}
\hline Biosimilar & Study details & Status/published results & Ref. \\
\hline \multirow[t]{2}{*}{ PF-05280014 (Pfizer) } & $\begin{array}{l}\text { Phase: I } \\
\text { Indication: none (healthy volunteers) } \\
\text { Concomitant treatment: none } \\
\mathrm{n}=101 \\
\text { Primary end point: } \mathrm{PK}\left(\mathrm{C}_{\text {max }^{\prime}} \mathrm{AUC}_{0-\infty^{\prime}} \mathrm{AUC}_{0-\text { last }}\right) \\
\text { Design: equivalence }\end{array}$ & $\begin{array}{l}\text { Complete } \\
\text { PK equivalence demonstrated for PF- } 05280014 \\
\text { vs EU-TTZ and US-TTZ } \\
\text { - } 90 \% \mathrm{Cl} \text { for ratios of } \mathrm{C}_{\text {max }^{\prime}} \mathrm{AUC}_{0-\infty} \text { and } \mathrm{AUC} \mathrm{C}_{0 \text {-last }} \\
\text { were all within } 80-125 \% \text { equivalence margins } \\
\text { for all three comparisons }\end{array}$ & [33] \\
\hline & $\begin{array}{l}\text { Phase: III } \\
\text { Indication: HER2+ early breast cancer } \\
\text { Concomitant treatment: docetaxel and } \\
\text { carboplatin } \\
\mathrm{n}=226 \\
\text { Primary end point: PK (steady state } \mathrm{C}_{\text {trough }} \text { ) } \\
\text { Design: equivalence }\end{array}$ & $\begin{array}{l}\text { Complete } \\
\text { Equivalence of primary end point } \\
\text { demonstrated (data not yet available) }\end{array}$ & \\
\hline \multirow[t]{2}{*}{ ABP 980 (Amgen) } & $\begin{array}{l}\text { Phase: I } \\
\text { Indication: none (healthy volunteers) } \\
\text { Concomitant treatment: none } \\
\mathrm{n}=118 \\
\text { Primary end point: } \mathrm{PK}\left(\mathrm{AUC}_{0-\infty}\right) \\
\text { Design: equivalence }\end{array}$ & $\begin{array}{l}\text { Complete } \\
\text { PK equivalence demonstrated for ABP } 980 \text { vs } \\
\text { TTZ } \\
\text { - Geometric mean ratio }(90 \% \mathrm{Cl}) \text { of } \mathrm{AUC}_{0-\infty^{\prime}} 0.90 \\
(0.85,0.94)\end{array}$ & {$[37]$} \\
\hline & $\begin{array}{l}\text { Phase: III } \\
\text { Indication: HER2+ early breast cancer } \\
\text { Concomitant treatment: paclitaxel } \\
\mathrm{n}=725 \\
\text { Primary end point: } \mathrm{pCR} \\
\text { Design: equivalence }\end{array}$ & $\begin{array}{l}\text { Complete } \\
\text { ABP } 980 \text { noninferior in terms of efficacy }\end{array}$ & [36] \\
\hline & $\begin{array}{l}\text { Phase: III } \\
\text { Indication: nonsquamous non-small-cell lung } \\
\text { cancer } \\
\text { Concomitant treatment: carboplatin and } \\
\text { paclitaxel } \\
\mathrm{n}=642 \\
\text { Primary end point: risk ratio of ORR } \\
\text { Design: equivalence }\end{array}$ & $\begin{array}{l}\text { Complete } \\
\text { Equivalence of primary end point } \\
\text { demonstrated for ABP } 215 \text { vs BVZ, and } \\
\text { comparable safety and immunogenicity } \\
\text { - Risk ratio for ORR }(90 \% \mathrm{Cl}), 0.93(0.80,1.09) \\
\text { - ORR, } 39.0 \text { vs } 41.7 \%\end{array}$ & {$[39]$} \\
\hline \multicolumn{4}{|c|}{ 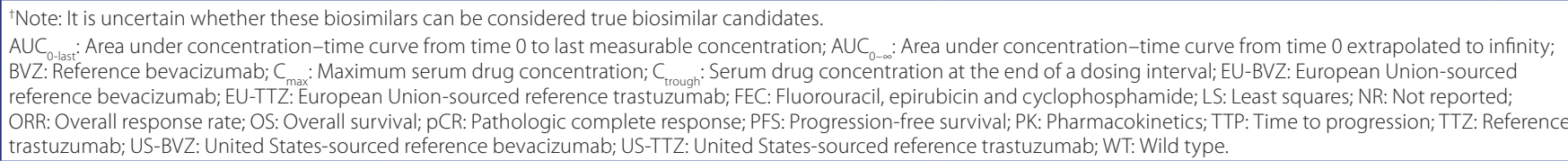 } \\
\hline
\end{tabular}




\section{Table 2. Clinical trials of other key biosimilars in development for the treatment of cancer (cont.).}

\begin{tabular}{|c|c|c|c|}
\hline Biosimilar & Study details & Status/published results & Ref. \\
\hline \multirow[t]{2}{*}{ PF-06439535 (Pfizer) } & $\begin{array}{l}\text { Phase: I } \\
\text { Indication: none (healthy volunteers) } \\
\text { Concomitant treatment: none } \\
\mathrm{n}=102 \\
\text { Primary end point: } \mathrm{PK}\left(\mathrm{C}_{\text {max }^{\prime}} \mathrm{AUC}_{0-\infty^{\prime}} \mathrm{AUC}_{0 \text {-last }}\right) \\
\text { Design: equivalence }\end{array}$ & 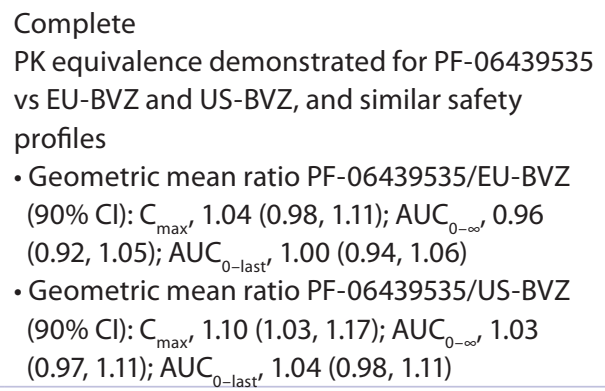 & [40] \\
\hline & $\begin{array}{l}\text { Phase: III } \\
\text { Indication: advanced nonsquamous non-small- } \\
\text { cell lung cancer } \\
\text { Concomitant treatment: paclitaxel and } \\
\text { carboplatin } \\
\mathrm{n}=710 \text { (estimated) } \\
\text { Primary end point: ORR at week } 19 \\
\text { Design: NR }\end{array}$ & $\begin{array}{l}\text { Ongoing } \\
\text { Estimated completion date: December } 2017\end{array}$ & [41] \\
\hline \multicolumn{4}{|c|}{ 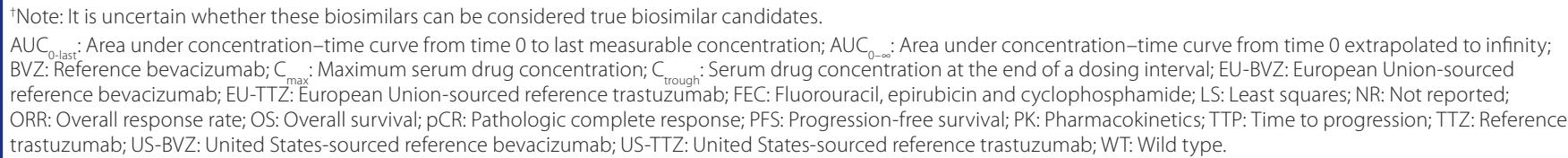 } \\
\hline
\end{tabular}

metastatic breast cancer demonstrated equivalence of the primary end point of overall response rate of the biosimilar versus its reference product in combination with paclitaxel as first-line treatment [34]. In a separate Phase III trial, PK equivalence of PF-05280014 and reference trastuzumab was demonstrated in patients with HER2-positive early breast cancer in combination with docetaxel and carboplatin. This trial also aims to compare efficacy, safety and immunogenicity of the two treatments in the neoadjuvant setting of breast cancer, although these data are not yet available [34].

ABP 980 has been compared with reference trastuzumab in a Phase III trial in women with HER-positive early breast cancer. The primary efficacy end point was the percentage of patients with pCR. Results from this trial demonstrated that the biosimilar was noninferior to reference trastuzumab in terms of efficacy [36]. Despite reaching the approval application stage of the development process, there is a lack of published data for SB3.

- Clinical trials of bevacizumab biosimilars ABP 215 has shown comparable PK to US- and EU-sourced reference bevacizumab in healthy male volunteers [38]. A Phase III trial has also compared efficacy and safety of up to six cycles of ABP 215 versus reference bevacizumab in combination with paclitaxel and carboplatin in previously untreated patients with advanced nonsquamous non-small-cell lung cancer. Clinical equivalence was demonstrated for the primary efficacy outcome (risk ratio of ORR). Similar safety and immunogenicity profiles were observed in the different treatment groups [39]. Applications for approval of ABP 215 were submitted to both the FDA and EMA at the end of 2016.

PF-06439535 has followed a similar clinical program to ABP 215, first demonstrating PK equivalence and comparable safety to both US-sourced and EU-sourced reference bevacizumab in healthy males [40]. A Phase III trial is currently ongoing to assess the efficacy and safety of PF-06439535 in previously untreated patients with advanced nonsquamous nonsmall-cell lung cancer in combination with paclitaxel and carboplatin [41].

\section{Conclusion}

The development of biosimilars of key biologic anticancer drugs looks set to transform the oncotherapy landscape, conferring an important benefit in terms of treatment costs and accessibility. 
Early in 2017, CT-P10 became the first monoclonal antibody biosimilar cancer therapeutic to receive international regulatory approval after a series of studies demonstrated equivalence to its reference product, rituximab. Of note, studies that have followed this process have yielded promising results for other rituximab candidate biosimilars as well as candidate biosimilars of other targeted therapies with reference products approaching expiry, including trastuzumab and bevacizumab. Clinical trials are essential to the approval process, with Phase I studies used to compare PK usually being performed before Phase III equivalence or noninferiority efficacy studies. While it is crucial that these studies show no clinically meaningful differences between a candidate biosimilar and reference product, this process is far simpler than establishing safety and efficacy data for a novel biological therapy, allowing for accelerated approval. The possibility to extrapolate to other indications of the reference product may also extend this benefit to other disease areas beyond those studied in biosimilar trials.

\section{EXECUTIVE SUMMARY}

\section{Background}

- Biosimilar cancer therapeutics represent an important opportunity to improve global access to key biological therapies by increasing affordability without compromising efficacy or safety.

- The first monoclonal antibody biosimilar anticancer drug to receive international regulatory approval was CT-P10 (Truxima ${ }^{\circledR}$ ); a CD20-targeted monoclonal antibody and biosimilar of rituximab. The studies that generated the 'totality of evidence' leading to CT-P10 approval followed a well-defined, stepwise pathway as defined by the EMA and FDA.

\section{Oncology clinical trials of CT-P10}

- Equivalence of pharmacokinetics and noninferiority of efficacy of CT-P10 compared with RTX was demonstrated in a Phase III study of treatment-naive advanced-stage follicular lymphoma (FL) when coadministered with CVP (cyclophosphamide, vincristine and prednisone).

- A Phase III trial evaluating biosimilarity of CT-P10 and RTX in low-tumor-burden FL is ongoing.

\section{Extrapolation of indications}

- Clinical trials evaluating biosimilarity are typically performed in only one or two indications. Following approval, extrapolation to further indications may be permitted on a case-by-case basis as determined by scientific justification, often involving consideration of the mechanisms of action of the biosimilar and reference product.

\section{Clinical trials of other biosimilar cancer therapeutics}

- Phase III clinical trials evaluating rituximab biosimilar candidates, such as GP2013 and ABP 798, have also been performed, or are ongoing, in patients with FL.

- Despite the expiry of patents on cetuximab, few candidate biosimilars have entered clinical evaluation, and the true biosimilar nature of those that have been assessed (CMAB009 and STI-001) is questionable due to differences in manufacture and composition compared with cetuximab.

- Several biosimilars of trastuzumab - MYL-14010, CT-P6 and SB3 - have been submitted for approval following demonstration of their biosimilarity in clinical trials in the settings of early and metastatic HER2-positive breast cancer.

- ABP 215 was comparable to its reference product, bevacizumab, in a Phase III study of advanced nonsquamous nonsmall-cell lung cancer, while another candidate biosimilar, PF-06439535, is underassessment in a similar Phase III trial following demonstration of pharmacokinetic equivalence and comparable safety in a Phase I trial.

\section{Conclusion}

- CT-P10 was the first monoclonal antibody biosimilar cancer therapeutic to receive international regulatory approval by following a cumulative, stepwise series of clinical studies to demonstrate biosimilarity to its reference product, rituximab.

- Other biosimilar agents that follow this study process are showing promising results, including other rituximab biosimilar agents and biosimilars for other reference products that are approaching patent expiry, including trastuzumab and bevacizumab. 


\section{Future perspective}

As described in this article, there are many biosimilar candidates for the treatment of cancer progressing through the clinical pipeline. With the recent approval of CT-P10 as the first monoclonal antibody biosimilar for use in oncology indications, we can expect at least some of these candidates to follow suit and enter the marketplace once patent expiry of their originator biologics has been reached. Key to uptake of these biosimilars into clinical practice will be well-informed healthcare professionals who understand the evidence supporting their use. This relies on timely publication of comparative data from both nonclinical studies and clinical trials. Furthermore, clear delineation between biosimilars and biomimics must be maintained as the latter often lack the rigorous clinical studies that are required for approval of true biosimilars by major regulatory agencies. These copies also often lack adequate pharmacovigilance; therefore, considering them equal to true biosimilars will likely detract from the high standards and level of stringency that are associated with the biosimilar regulatory process, and reduce overall confidence in biosimilars.

\section{Financial \& competing interests disclosure}

WS Kim has received research funding from Kyowa Kirin, Johnson \& Johnson, CELLTRION, Roche and Novartis, and personal fees from Johnson \& Johnson, CELLTRION and Roche outside the submitted work. B Coiffier has received personal fees from Gilead, Celgene, CELLTRION, Roche, MorphoSys, MedImmune, Mundipharma and Pfizer outside the submitted work. H-C Kwon and SY Kim are employees of CELLTRION Healthcare Co., Ltd. The authors have no other relevant affiliations or financial involvement with any organization or entity with a financial interest in or financial conflict with the subject matter or materials discussed in the manuscript apart from those disclosed.

Writing assistance was utilized in the production of this manuscript. Medical writing support during the preparation of this article was provided by Louisa Lyon, DPhil and Alice Wareham, PhD (Aspire Scientific, Bollington, UK) and was funded by CELLTRION Healthcare Co., Ltd (Incheon, Republic of Korea).

\section{References}

Papers of special note have been highlighted as:

- of interest; $\bullet$ of considerable interest

1 US Food \& Drug Administration. Scientific considerations in demonstrating biosimilarity to a reference product. Guidance for industry. www.fda.gov/downloads/drugs/guidances/ ucm291128.pdf

2 European Medicines Agency. Guideline on similar biological medicinal products containing biotechnology-derived proteins as active substance: non-clinical and clinical issues. www.ema.europa.eu/docs/en_GB/ document_library/Scientific_ guideline/2015/01/WC500180219.pdf

3 European Medicines Agency. Committee for Human Medicinal Products Assessment report for Truxima (procedure no. EMEA/ H/C/004112/0000).

www.ema.europa.eu/docs/en_GB/ document_library/EPAR___Public_ assessment_report/human/004112/ WC500222695.pdf

- Assessment report for CT-P10 (Truxima) detailing the clinical and nonclinical evidence supporting its approval for marketing authorization by the EMA.

4 Maloney DG, Smith B, Rose A. Rituximab: mechanism of action and resistance. Semin. Oncol. 29(1 Suppl. 2), 2-9 (2002).
5 Buske C, Ogura M, Kwon H-C, Yoon SW. An introduction to biosimilar cancer therapeutics: definitions, rationale for development and regulatory requirements. Future Oncol. 13(15s), 5-16 (2017).

6 Bui LA, Taylor C. Developing clinical trials for biosimilars. Semin. Oncol. 41(Suppl. 1), S15-S25 (2014).

7 European Medicines Agency. Guideline on similar biological medicinal products. www. ema.europa.eu/docs/en_GB/document_ library/Scientific_guideline/2014/10/ WC500176768.pdf

8 European Medicines Agency. Guideline on similar biological medicinal products containing monoclonal antibodies - nonclinical and clinical issues. www.ema.europa. eu/docs/en_GB/document_library/ Scientific_guideline/2012/06/ WC500128686.pdf

- EMA guidelines that include additional considerations for monoclonal antibody biosimilars in cancer indications.

9 European Medicines Agency. Guideline on the investigation of bioequivalence. www. ema.europa.eu/docs/en_GB/document_ library/Scientific_guideline/2010/01/ WC500070039.pdf

- EMA guidelines on the requirements for demonstrating bioequivalence between medicinal products, including recommended acceptance limits.

10 Clinical Trials Database: NCT02162771. https://clinicaltrials.gov/ct2/show/ NCT02162771

11 Kim W, Ogura M, Buske C et al. Global phase I/III pharmacokinetic and efficacy study comparing CT-P10, a biosimilar candidate to the rituximab reference product in patients with advanced stage follicular lymphoma (AFL). Blood 126, 5111 (2015).

- Abstract detailing the design of the Phase III trial that compared CT-P10 with US-sourced reference rituximab in patients with advanced follicular lymphoma (FL).

12 Coiffier B, Sancho J-M, Jurczak W et al. Pharmacokinetic and safety of CT-P10, a biosimilar candidate to the rituximab reference product, in patients with newly diagnosed advanced stage follicular lymphoma (AFL). Blood 128(22), Abstract 1807 (2016).

- Phase III study of CT-P10 compared with US-sourced reference rituximab in patients with advanced FL plus chemotherapy, demonstrating pharmacokinetic equivalence and comparable safety and immunogenicity.

13 Yoo D-H, Suh C-H, Shim SC et al. A 
multicentre randomised controlled trial to compare the pharmacokinetics, efficacy and safety of CT-P10 and innovator rituximab in patients with rheumatoid arthritis. Ann. Rheum. Dis. 76(3), 566-570 (2017).

14 Suh C-H, Kasay A, El-Khouri E et al. Pharmacokinetics and safety of three formulations of rituximab (CT-P10, US-sourced innovator rituximab and EU-sourced innovator rituximab) in patients with rheumatoid arthritis: results from phase III randomized controlled trial over 24 weeks. Arthritis Rheumatol. 68(Suppl. 10), Abstract 1634 (2016).

15 Yoo D-H, Majstorovic L, Kasay A et al. Efficacy and safety of CT-P10, rituximab biosimilar candidate, and innovator rituximab in patients with rheumatoid arthritis: results from Phase 3 randomized controlled trial over 24 weeks. Arthritis Rheumatol. 68(Suppl. 10), Abstract 1635 (2016).

16 Jurczak W, Ilidia M, Govindbabu K et al. A Phase III efficacy and safety study of the proposed rituximab biosimilar GP2013 versus rituximab in patients with previously untreated advanced follicular lymphoma. Blood 128(22), Abstract 1809 (2016).

- Phase III study of GP2013 compared with EU-sourced reference rituximab in patients with advanced FL plus chemotherapy, demonstrating equivalent efficacy and comparable pharmacokinetics, pharmacodynamics and safety.

17 Smolen J, Scheinberg M, Tony H-P, Zhu P, Shisha T. FRI0222 pharmacokinetics, pharmacodynamics, safety and efficacy of proposed rituximab biosimilar (GP2013) vs. EU-approved rituximab (RTX) in patients with rheumatoid arthritis: results from a randomized controlled trial (GP13-201) over 52 weeks. Ann. Rheum. Dis. 75(Suppl. 2), 512-513 (2016)

18 Cohen S, Emery P, Greenwald M et al. A phase I pharmacokinetics trial comparing PF-05280586 (a potential biosimilar) and rituximab in patients with active rheumatoid arthritis. Br. J. Clin. Pharmacol. 82(1), 129-138 (2016).

19 Clinical Trials Database: NCT02213263. https://clinicaltrials.gov/ct2/show/ NCT02213263

20 Amgen. Clinical Trial Summary 20130109. Study to assess if ABP798 is safe \& effective in treating non Hodgkin lymphoma compared to rituximab (JASMINE). www.amgentrials.com/amgen/trialsummary. aspx?studyid $=20130109$

21 Clinical Trials Database: NCT02792699. https://clinicaltrials.gov/ct2/show/ NCT02792699

22 Clinical Trials Database: NCT02747043. https://clinicaltrials.gov/ct2/show/ NCT02747043

23 Clinical Trials Database: NCT02260804. https://clinicaltrials.gov/ct2/show/ NCT02260804

24 World Health Organization. Guidelines on evaluation of similar biotherapeutic products (SBPs). www.who.int/biologicals/areas/biological_ therapeutics/BIOTHERAPEUTICS_FOR_ WEB_22APRIL2010.pdf

25 Ogura M, Coiffier B, Kwon H-C, Yoon SW. Scientific rationale for extrapolation across cancer indications: case study of CT-P10. Future Oncol. 13(15s), Article 4 in this supplement, (2017).

26 Wang C, He X, Zhou B et al. Phase 1 study of anti-epidermal growth factor receptor monoclonal antibody in patients with solid tumors. MAbs 3(1), 67-75 (2011).

27 Clinical Trials Database: NCT01550055. https://clinicaltrials.gov/ct2/show/record/ NCT01550055

28 Sorrento Therapeutics. Press release: Sorrento announces positive data from Phase 3 studies of biosimilar antibodies, STI-001 and STI-002. http://sorrentotherapeutics.com/ news $/$ news-display/ ?id $=122589$

29 Waller C, Vutikullird A, Lawrence T et al. A pharmacokinetics (PK) bioequivalence trial of proposed trastuzumab biosimilar, Myl-1401O (A) vs EU-Herceptin (B) and US-Herceptin (C). Eur. J. Cancer 72 (Suppl. 1), S40-S41 (2017).

30 Rugo HS, Barve A, Waller CF et al. Effect of a proposed trastuzumab biosimilar compared with trastuzumab on overall response rate in patients with ERBB2 (HER2)-positive metastatic breast cancer: a randomized clinical trial. JAMA 317(1), 37-47 (2017).

- Phase III study of MYL-1401O compared with reference trastuzumab in patients with metastatic breast cancer plus chemotherapy, demonstrating equivalent efficacy and comparable safety.

31 Esteva F, Lee S, Stebbing J, Winkle P, Wood-Horrall R, Young Lee S. P137 Phase I clinical trial comparing PK and safety of trastuzumab and its biosimilar candidate CT-P6. Breast 32 (Suppl. 1), S68-S69 (2017).

32 Clinical Trials Database: NCT02162667. https://clinicaltrials.gov/ct2/show/ NCT02162667
33 Yin D, Barker KB, Li R et al. A randomized phase 1 pharmacokinetic trial comparing the potential biosimilar PF-05280014 with trastuzumab in healthy volunteers (REFLECTIONS B327-01). Br. J. Clin. Pharmacol. 78(6), 1281-1290 (2014).

34 Pfizer. Press release: Pfizer announces positive top-line results from the pivotal comparative REFLECTIONS B3271002 study for PF-05280014, a potential biosimilar to Herceptin $^{\circledR}$ (trastuzumab). www.pfizer.com/news/press-release/ press-release-detail/pfizer_announces_ positive_top_line_results_from_the_pivotal_ comparative_reflections_b3271002_study_ for_pf_05280014_a_potential_biosimilar_ to_herceptin_1_trastuzumab

35 Clinical Trials Database: NCT02187744. www.clinicaltrials.gov/ct2/show/ NCT02187744

36 Amgen. Press release: Amgen and Allergan announce top-line results from Phase 3 study evaluating ABP 980 compared with trastuzumab in patients with human epidermal growth factor receptor 2-positive early breast cancer.

www.amgen.com/media/newsreleases/2016/07/amgen-and-allerganannounce-top-line-results-from-phase-3study-evaluating-abp-980-compared-withtrastuzumab-in-patients-with-humanepidermal-growth-factor-receptor-2-positiveearly-breast-cancer/

37 Wisman LA, De Cock EP, Reijers JA et al. A phase I dose-escalation and bioequivalence study of a trastuzumab biosimilar in healthy male volunteers. Clin. Drug Investig. 34(12), 887-894 (2014).

38 Markus R, Kaur P, Chow V et al. Results of functional testing and pharmacokinetics comparing ABP 215 to bevacizumab. J. Clin. Oncol. 33(Suppl. 3), Abstract 711 (2015).

39 Thatcher N, Thomas M, Paz-Ares L et al. Randomized, double-blind, phase 3study evaluating efficacy and safety of ABP 215 compared with bevacizumab in patients with non-squamous NSCLC. J. Clin. Oncol. 34(Suppl.), Abstract 9095 (2016).

40 Knight B, Rassam D, Liao S, Ewesuedo R. A Phase I pharmacokinetics study comparing PF-06439535 (a potential biosimilar) with bevacizumab in healthy male volunteers. Cancer Chemother. Pharmacol. 77(4), 839-846 (2016).

41 Clinical Trials Database: NCT02364999. https://clinicaltrials.gov/ct2/show/ NCT02364999

42 Mysler E, Pineda C, Horiuchi T et al. Clinical and regulatory perspectives on biosimilar 
SUPPLEMENT Kim, Coiffier, Kwon \& Kim

therapies and intended copies of biologics in rheumatology. Rheumatol. Int. 36(5), 613-625 (2016).

- Review discussing the key concepts of biosimilars, including clinical and regulatory considerations, and the important differences between biosimilars and intended copies.
43 Generics and Biosimilars Initiative. Positive Phase III results for cetuximab and infliximab copy biologicals.

www.gabionline.net/Biosimilars/Research/ Positive-Phase-III-results-for-cetuximab-andinfliximab-copy-biologicals 